\title{
Iron deficiency anaemia in patients with inflammatory bowel disease: National Consultant for Gastroenterology Working Group Recommendations
}

\author{
Magdalena Kaniewska1 ${ }^{1}$, Witold Bartnik ${ }^{2,3}$, Maciej Gonciarz ${ }^{4}$, Maria Kłopocka ${ }^{5}$ Krzysztof Linke ${ }^{6}$, \\ Ewa Małecka-Panas ${ }^{7}$, Piotr Radwan ${ }^{8}$, Jarosław Reguła ${ }^{2,3}$, Grażyna Rydzewska ${ }^{1,9}$ \\ 'Department of Gastroenterology with IBD Subdivision of Central Clinical Hospital of Ministry of Internal Affairs, Warsaw, \\ Poland \\ 2Department of Gastroenterology, Hepatology and Clinical Oncology, Medical Postgraduate Education Centre, Warsaw, \\ Poland \\ ${ }^{3}$ Department of Gastrointestinal Oncology, Maria Sklodowska-Curie Clinical Oncology Institute, Warsaw, Poland \\ ${ }^{4}$ Department of Gastroenterology and Gastrointestinal Oncology, St. Barbara Hospital, Sosnowiec, Poland \\ ${ }^{5}$ Gastroenterology Nursing Unit, Centre for Therapeutic Endoscopy, University Hospital No 2, Collegium Medicum in Bydgoszcz, \\ Nicolaus Copernicus University in Torun, Poland \\ ${ }^{6}$ Department of Gastroenterology, Human Nutrition, and Internal Diseases, Poznan University of Medical Sciences, Poznan, \\ Poland \\ 'Department of Gastrointestinal Diseases, Medical University of Lodz, Lodz, Poland \\ ${ }^{8}$ Department of Gastroenterology and Endoscopy, Medical University of Lublin, Lublin, Poland \\ ${ }^{9}$ Faculty of Health Sciences, Jan Kochanowski University, Kielce, Poland
}

Prz Gastroenterol 2014; 9 (5): 259-263

DOI: $10.5114 / p g .2014 .46159$

Key words: Crohn's disease, ulcerative colitis, iron deficiency anaemia, anaemia in chronic disease, intravenous iron supplements.

Address for correspondence: Magdalena Kaniewska MD, PhD, Department of Gastroenterology with IBD Subdivision of Central Clinical Hospital of Ministry of Internal Affairs, 137 Woloska St, 02-507 Warsaw, Poland, phone: +48 22508 12 40, e-mail: kaniewscy@o2.pl

\begin{abstract}
Anaemia is a common complication associated with inflammatory bowel diseases (Crohn's disease and ulcerative colitis). It substantially impairs quality of life, makes therapy more complicated, and increases costs of treatment. It seems that anaemia therapy is suboptimal in this group of patients in the Polish population. The recommendations presented below provide iron deficiency anaemia management clues in patients with inflammatory bowel disease.
\end{abstract}

\section{Introduction}

Inflammatory bowel diseases (IBD), including Crohn's disease (CD) and ulcerative colitis (UC), are chronic gastrointestinal illnesses of multifactorial aetiology, which proceed with periods of relapse and remission. These conditions are often associated with extraintestinal manifestations or complications, and iron deficiency anaemia is foremost among them. The pathomechanism of anaemia in IBD patients is multifactorial, but iron deficiency seems to be the most important cause. Anaemia significantly impairs quality of life and modifies host immunological status and morbidity, especially in terms of concomitant infections; it also appears to be a mortality-increasing factor [1-3]. Iron deficiency anaemia management in IBD patients continues to be suboptimal in Poland, and reports presented at European Crohn's and Colitis Organisation (ECCO) meetings suggest blood transfusions are used too freely in this group of patients.

The panel of invited experts reached a consensus in terms of defining the most important concepts of anaemia in IBD, and they discussed optimal diagnostic and therapeutic strategy. 


\section{Diagnosis}

Regarding its significant impact on quality of life and mortality, every IBD patient should be tested for anaemia. If haemoglobin levels below lower limit of normal are found, diagnostic workup commencement is of utmost importance.

\section{Comments}

The World Health Organisation defined the lower limit of normal for haemoglobin and haematocrit according to age and sex [2, 3] (Table I).

There is no need to establish a new definition of anaemia in IBD, so in this patient group standard criteria are adopted regarding age, sex, and potential pregnancy [1].

\section{Biochemical tests}

Inflammatory bowel diseases patients should have haemoglobin, ferritin, and C-reactive protein (CRP) measured at least every 6 to 12 months when in remission or with mild disease, and every 3 months when moderate to severe relapse occurs.

Patients at high risk of vitamin $B_{12}$ or folic acid deficiency (particularly with small intestinal invoIvement or resection, as well as ileal pouch) should have vitamin $B_{12}$ and folic acid levels assessed at least yearly, especially when macrocytosis is detected.

Once low haemoglobin is detected, at least ferritin, transferrin saturation (TfS), and CRP measurement is recommended.

Table I. Haemoglobin (HGB) and haematocrit (Ht) lower limit of normal, according to the WHO [3]

\begin{tabular}{lccc} 
Group & $\begin{array}{c}\text { HGB } \\
{[\mathrm{g} / \mathrm{dl}]}\end{array}$ & $\begin{array}{c}\text { HGB } \\
{[\mathrm{mmol} / \mathrm{l}]}\end{array}$ & Ht [\%] \\
\hline Children 6 months - 5 years & 11 & 6.83 & 33 \\
\hline Children 5-11 years & 11.5 & 7.14 & 34 \\
\hline Children > 12 years & 12 & 7.45 & 36 \\
\hline Pregnant women & 11 & 6.83 & 33 \\
\hline Adult females & 12 & 7.45 & 36 \\
\hline Adult males & 13 & 8.07 & 39
\end{tabular}

\section{Comments}

In differentiation of the most frequent types of anaemia, such as iron deficiency anaemia (IDA) and anaemia in chronic disease (ACD), the algorithm presented in Table II can be used [4-6]. It is particularly important in IBD patients because both types of anaemia commonly coexist; moreover, active inflammation (based on CRP assessment) alters interpretation of other laboratory results.

\section{Iron deficiency anaemia}

Ferritin is the best single diagnostic parameter in iron deficiency anaemia detection.

\section{Comments}

Ferritin measurement is much more useful than the other parameters discussed earlier. However, it must be kept in mind that ferritin is an acute phase protein so test results have to be interpreted in correlation with the disease activity. Iron deficiency in patients with absent biochemical inflammatory markers is reflected by ferritin levels $<30 \mu \mathrm{g} / \mathrm{l}$ (TfS $<16 \%$ ). In active inflammatory process, ferritin levels may be as low as $100 \mu \mathrm{g} / \mathrm{l}$ when iron stores are normal and $>800 \mu \mathrm{g} / \mathrm{l}$ if iron overload has occurred [1,7]. Iron deficiency in IBD may have various backgrounds based on disease phase, previous surgery, malabsorption, or, above all, increased losses associated with active inflammation.

Independent of diminished iron levels anaemia assessment should include:

- potential comorbidity (malignancy, infection),

- treatment side effects (thiopurine, methotrexate, sulphasalazine).

In chronic disease-related anaemia with clinical symptoms or biochemical markers of inflammation,

Table II. Differential diagnosis of iron deficiency anaemia (IDA) and anaemia in chronic inflammatory disease $(A C D)$

\begin{tabular}{lccc} 
Laboratory parameter & IDA & ACD & IDA + ACD \\
\hline Haemoglobin & $\downarrow$ & $\downarrow$ & $\downarrow$ \\
\hline C-reactive protein (CRP) & Normal & $\uparrow$ & $\uparrow$ \\
\hline Serum ferritin & $\downarrow$ & $\uparrow$ & $\uparrow$ or normal \\
\hline Transferrin saturation (TfS) & $\downarrow$ & $\downarrow$ & $\downarrow$ \\
\hline $\begin{array}{l}\text { Soluble transferrin receptor } \\
\text { (STfR) }\end{array}$ & $\uparrow$ & Low $(<1)$ & $\uparrow$ or normal \\
\end{tabular}


diagnostic criteria are as follows: ferritin >100 $\mu \mathrm{g} / \mathrm{l}$ and TfS $<16 \%$. If ferritin levels are between $30 \mu \mathrm{g} / \mathrm{l}$ and $100 \mu \mathrm{g} / \mathrm{l}$, the coexistence of iron deficiency anaemia and anaemia in chronic disease seems to be most likely [6].

\section{Treatment}

In IBD patients with associated anaemia the aim of treatment strategy is normalisation of haemoglobin and iron levels. Ferritin and transferrin saturation increase above borderline values should be considered as well.

\section{Comments}

The aim of anaemia therapy in IBD is to improve quality of life, decrease the frequency and duration of hospital admissions, and avoid blood transfusions. It is usually achieved by normalising haemoglobin, ferritin, and TfS levels.

Anaemia management should be considered in every patient with low haemoglobin level. The decision about pharmacotherapy depends on anaemia degree, symptoms, and potential drug side effects. Quality of life decrease without clinical symptoms or signs of anaemia and with merely low laboratory parameters such as transferrin saturation, ferritin, or iron levels has to be taken into account [4]. When iron deficiency with borderline haemoglobin concentration is detected, iron supplementation should be considered and discussed with the patient.

Before iron deficiency anaemia management is commenced it should be born in mind that oral iron can enhance gastrointestinal inflammatory process by toxic mucosal damage induction, which is caused by hydroxyl free radicals generated during iron oxidation triggered by hydrogen peroxide (Fenton reaction) $[8,9]$. In addition, oral iron is often poorly tolerated in this group of patients. Regarding better effectiveness and tolerability, intravenous iron is preferred in IBD patients. In particular, intravenous iron formulation is recommended in severe IBD when oral supplementation is ineffective or poorly tolerated (in $20 \%$ of IBD patients), when haemoglobin is $<10 \mathrm{~g} / \mathrm{dl}$, or during erythropoietin administration [10].

\section{Iron deficiency assessment}

For iron deficiency assessment the Ganzoni formula is commonly used: iron deficit $[\mathrm{mg}]=$ body weight $[\mathrm{kg}] \times$ (target haemoglobin - actual haemoglobin) $[\mathrm{g} / \mathrm{l}] \times 0.24+500 \mathrm{mg}$. In patients with less than $35 \mathrm{~kg}$ body weight, an iron dose of $15 \mathrm{mg} / \mathrm{kg}$ is suggested.
Table III. Iron dosage based on baseline patient haemoglobin (HGB) and body weight

\begin{tabular}{ccc} 
HGB [g/dl] & $\begin{array}{c}\text { Body weight } \\
<70 \mathrm{~kg}\end{array}$ & $\begin{array}{c}\text { Body weight } \\
>70 \mathrm{~kg}\end{array}$ \\
\hline$>10$ & $1000 \mathrm{mg}$ & $1500 \mathrm{mg}$ \\
\hline $7-10$ & $1500 \mathrm{mg}$ & $2000 \mathrm{mg}$
\end{tabular}

\section{Comments}

In most previous reports iron deficiency was established using the Ganzoni formula [11]. However, it seems that iron deficit calculated using this method does not reflect real iron requirements.

Among others, it was demonstrated in a Ferinject trial in which only $26.5 \%$ of patients receiving full iron dose calculated on the Ganzoni formula basis were able to reach the desired ferritin level $(100-800 \mu \mathrm{g} / \mathrm{l})$ at the end of it [12]. Recently an alternative iron dosage scheme based on baseline patient haemoglobin and body weight was used in the FERGIcor trial [13] and in the PROCEED trial [14] (Table III).

In the two above-mentioned trials the efficacy and safety of intravenous iron compounds were assessed, as well as a new and simplified dosing scheme for Monover and Ferinject, and the Ganzoni formula for Venofer. Patients treated with Ferinject received approximately $200 \mathrm{mg}$ overall extra dose of iron as compared with Venofer patients. Although significant haemoglobin increase was achieved in $73 \%$ of patients, recommended ferritin elevation $>100 \mu \mathrm{g} / \mathrm{l}$ was reported in $31 \%$ of patients only [13]. Monover administered in a single dose ranging from $1000 \mathrm{mg}$ to $2000 \mathrm{mg}$ allowed ferritin, haemoglobin, and TfS levels the be kept stable over a 12-month period [14]. It would seem that iron requirement calculations based on general rules do not always prove correct in IBD patients.

The Working Group encourages physicians to familiarise themselves with a tool called a Ferroscope, created to facilitate therapeutic decision making in IBD patients with iron deficiency [15]. It includes several thousand scenarios involving sex, haemoglobin and ferritin levels, disease activity, previous iron deficiency treatment, clinical symptoms of anaemia, or additional factors increasing the need for iron. When data is introduced into the system it is possible to gain clues regarding optimal patient management. Therapeutic options labelled as appropriate, uncertain, and inappropriate include iron administration orally, intravenously in low doses (< $500 \mathrm{mg}$ per single dose) or high doses ( $\geq 500 \mathrm{mg}$ per single dose), the addition of erythropoiesis stimulating drugs, or blood transfusion. The free catalogue is available online at: www. ferroscope.com. 
During treatment it is advisable to aim at gaining haemoglobin elevation by $2 \mathrm{~g} / \mathrm{l}$ or its normalisation within 4 weeks of therapy [4]. If sufficient therapeutic effect is lacking, treatment intensification (oral to intravenous shift, intravenous formulation usage allowing high single dose administration, or erythropoiesis stimulating factor addition) or other coexisting anaemia cause exclusion should be considered. Regarding the appropriateness of iron deficit replacement within a 4-week treatment period, administration of higher single doses of iron seems beneficial as a therapeutic option in patients with severe anaemia [4, 6, 15]. Asymptomatic patients should have haemoglobin measured after 4 weeks of treatment, whereas patients with previous symptoms of anaemia are usually tested on an individual basis, depending on the patient condition and baseline results. Ferritin elevation $>100 \mu \mathrm{g} / \mathrm{l}$ in patients on oral iron supplements is proof of treatment effectiveness. In patients treated intravenously, ferritin levels should be checked not earlier than 8 weeks post infusion [6].

\section{Intravenous iron compounds}

In Poland the following intravenous iron compounds are available: iron (III) - hydroxide sucrose complex (Venofer), iron (III) hydroxide low molecular weight dextran complex (Cosmofer), ferric isomaltose (Monover), and ferric carboxymaltose (Ferinject). Previously the administration of intravenous iron testing dose was obligatory, but currently it is not recommended. Close patient monitoring 30 min post every parenteral iron injection is advised.

Venofer may be administered three times a week until the calculated dose needed to replenish iron stores is reached. The maximal single dose of iron $(500 \mathrm{mg}$; $7 \mathrm{mg} / \mathrm{kg}$ body weight) with infusion time approxima-

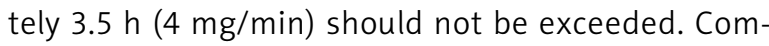
monly used doses are 200-300 mg infused in $100 \mathrm{ml}$ or $250 \mathrm{ml} 0.9 \% \mathrm{NaCl}$ within $45-90 \mathrm{~min}$.

Iron (III) hydroxide dextran complex (Cosmofer) is more stable and is slowly degraded, so it can be used in higher single doses. Recommended dosing is 100$200 \mathrm{mg}$ of iron 2-3 times per week, although it is also accepted to infuse maximal dose of $20 \mathrm{mg} / \mathrm{kg}$ body weight during one drip infusion lasting 4-6 h.

Ferric isomaltose (Monover) is a safe drug, which does not need a testing dose and may be administered in high single doses. Intravenous $100-500 \mathrm{mg}$ iron bolus injections given at a rate of up to $50 \mathrm{mg} / \mathrm{min}$ are recommended; doses of 100-200 $\mathrm{mg}$ can be repeated up to three times a week. A single high dose infusion can contain up to $20 \mathrm{mg}$ of iron per kg body weight. The infusion velocity depends on the amount of iron administered (doses not exceeding $1000 \mathrm{mg}$ are given within $30 \mathrm{~min}$, whereas higher doses are infused in 60 min time).

Ferric carboxymaltose (Ferinject), due to its pharmacokinetic properties, is a stable complex, as well as a safe and well tolerated iron compound. A single dose that can be administered safely during intravenous infusion lasting $15 \mathrm{~min}$ is $1000 \mathrm{mg}$ (15 mg/kg body weight). Drug infusion can be repeated as required.

\section{Erythropoietin therapy}

Erythropoietin is indicated in IBD patients with anaemia related mainly to chronic inflammatory disease and in subjects with insufficient response to intravenous iron, in whom IBD therapy is optimal [4].

\section{Comments}

Erythropoietin administration should be considered in patients with haemoglobin less than $10 \mathrm{~g} / \mathrm{dl}$ or in whom high dose intravenous iron therapy was unsuccessful (after 4 weeks of treatment). Such a therapy should by undertaken in patients with erythropoietin, sTfR, and TfS levels suggesting ineffectiveness of intravenous iron monotherapy [16].

\section{Vitamin $B_{12}$ and folic acid deficiency anaemia treatment}

In patients with identified vitamin $B_{12}$ or folic acid deficit, introduction of supplementation therapy is recommended.

\section{Blood transfusion}

Chronic gastrointestinal blood loss may occur in IBD patients. Repeated blood transfusions result in antibody formation, and as such their use should be limited to exceptional and emergency cases.

\section{Comments}

In every gastrointestinal bleeding associated with substantial haemoglobin drop, indication for blood transfusion should be assessed individually based on patient condition, age, comorbidities, and amount of blood lost. Blood transfusion does not replace intravenous iron therapy, which is sometimes applied in combination with erythropoietin. The patient should be monitored and further parenteral iron substitution scheduled post transfusion, even if haemoglobin level is normal [4]. 


\section{References}

1. Gasche C, Berstad A, Befrits R, et al. Guildelines on the diagnosis and management of iron deficiency and anemia in inflammatory bowel diseases. Inflamm Bow Dis 2007; 13: 1545-53.

2. Wilson A, Reyes E, Ofman J. Prevalance and outcomes of anemia in inflammatory bowel disease: a systemic review of the literature. Am J Med 2004; 116 (Suppl. 7A): 44s-9s.

3. Iron deficiency anemia: assessment, prevention and control, A guide of programme managers, Geneva, WHO, 2001, WHO/ $\mathrm{NHD} / 01.3$.

4. Gasche C, Lomer MC, Cavill I, et al. Iron, anemia, and inflammatory bowel diseases. GUT 2004; 53: 1190-7.

5. Duerksen DR, Fallows G, Bernstein CN. Vitamin B12 malabsorption in patients with limited ileal resection. Nutrition 2006; 22: 1210-3.

6. Reinish W, Staun M, Bhandari S, et al. State of the iron: how to diagnose and efficiently treat iron deficiency anemia in inflammatory bowel disease. J Crohns Colitis 2013; 7: 429-40.

7. Guyatt GH, Oxman AD, Ali M, et al. Laboratory diagnosis of iron-deficiency anemia: an overview. J Gen Intern Med 1992; 7: 145-53.

8. Gomollón F, Gisbert JP. Anemia and inflammatory bowel diseases. World J Gastrenetrol 2009; 15: 4659-65.

9. Kave P, Abdulla K, Wood J, et al. Iron-induced mucosal pathology of the upper gastrointestinal tract: a common finding in patients on oral iron therapy. Histopathology 2008; 53: 311-7.

10. Gisbert JP, Gomollón F. Common misconceptions in the diagnosis and management of anemia in inflammatory bowel disease. Am J Gastroenterol 2008; 103: 1299-307.

11. Auerbach M, Ballard H, Glaspy J. Clinical update: intravenous iron for anemia. Lancet 2007; 369: 1502-4.

12. Kulnigg S, Stoinov S, Simanenkov V, et al. A novel intravenous iron formulation for treatment of anemia in inflammatory bowel disease: the ferric carboxymaltose (FERINJECT) randomized controlled trial. Am J Gastroenterol 2008; 103: 1182-92.

13. Evstatiev R, Marteau P, Iqbal T, et al. FERGIcor, a randomized controlled trial on ferric carboxymaltose for iron deficiency anemia in inflammatory bowel disease. Gastroenterology 2011; 141: 846-53.

14. Reinish W, Staun M, Tandon RK, et al. A randomized, openlabel, non-inferiority study of intravenous iron isomaltoside 1,000 (Monover) compared with oral iron for treatment of anemia in IBD (PROCEED). Am J Gastroenterol 2013; 108: 1877-88.

15. Reinisch W, Chowers Y, Danese S, et al. The management of iron deficiency in inflammatory bowel disease an online tool developed by the RAND/UCLA appropriateness method. Aliment Pharmacol Ther 2013; 38: 1109-18.

16. Gasche C, Waldhoer T, Feichtenschlager T, et al. Prediction of response to iron sucrose in inflammatory bowel disease-associated anemia. Am J Gastroenterol 2001; 96: 2382-7.

Received: 8.09.2014

Accepted: 16.10 .2014 